\title{
INTERCULTURALIDAD Y DIVERSIDADES CULTURALES DESDE UNA PERSPECTIVA SITUADA
}

\author{
Héctor VÁZQUEZ1
}

\section{Resumen:}

El autor plantea los principales dilemas derivados de las tensiones generadas por las relaciones particularismo versus universalismo con relación a la diversidad étnica realmente existentes contextualizando el tratamiento del tema dentro de sus principales aportes al campo interdisciplinar configurado por la antropología socio-cultural. Sintetiza así su perspectiva acerca de la construcción de una Etnología del Conocimiento, de una Antropología Crítica, Emancipadora y Latinoamericana. De un abordaje Histórico -Crítico de la Antropología socio-cultural, y de los derechos diferenciados según cultura.

Palabras clave: Interculturalidad-Dialogo Intercultural- Etnología del ConocimientoDerechos Humanos -Razón situada-.

\begin{abstract}
:
The author poses the main dilemmas arising from the really existing tensions generated by particularism - universalism relations related to ethnic diversity, and conceptualizes the issue whithin his main contributions to the interdisciplinary field set by sociocultural anthropology. In this way he synthesizes his perspective about the construction of an Ethnology of Knowledge, a critical and Latin American Anthropology, and a historical-critical approach to the socio-cultural anthropology that considers human rights as differentiated according to culture.
\end{abstract}

Key words: Interculturalism-Intercultural dialogue - Ethnology of Knowledge - Human Rights - Located reason.

\section{Resumè :}

L `auteur pose les principaux dilemmes dérivés des tensions produites par les relations particularisme versus universalisme par rapport à la diversité éthnique réellement existent en contextualisant le traitement du sujet dans ses principaux apports au domaine intedisciplinaire formé par la anthropologie socio-culturel. Il synthétise ainsi

1 Dr. en Sociologie Université René Descartes. Paris VI. France. Investigador Superior del Consejo de Investigaciones de la Universidad Nacional de Rosario. Argentina. Director del Centro Interdisciplinario de Ciencias Etnolingüísticas y Antropológico Sociales .Facultad de Humanidades y Artes. Universidad Nacional de Rosario .Entre Ríos 758.Rosario (2.000). Argentina. fax 543414802675. E- Mail: hvazquez@hotmail.com 
sa perspective sur la construction d'une Ethnologie de la Connaissance, d'une Anthropologie Critique latinoaméricaine, latinoamericaine d'un abordage Historique et Critique de l'Anthropologie socio-culturelle, et des Droits de 1'Homme différencies selon culture.

Mots clé : Interculturalité- Dialogue Interculturelle- Ethnologie de la ConnaisanceDroits de 1'Homme. Raison située.

\section{Comentario introductorio.}

El tema que tratamos cruza el conjunto de los aportes que realizamos en el campo científico de las ciencias sociales, o al menos casi todos ellos. Desde los esfuerzo de elaboración de una Etnología del Conocimiento y la propuesta de una construcción genético - dialéctica de las sistematizaciones simbólicas y del desarrollo de los sistemas cognitivos, a la sistematización de una postura alternativa a lo que Claude Lèvi Strauss denominó Pensamiento Salvaje, y a la propuesta de un abordaje Histórico Crítico de las ciencias sociales y especialmente de la Antropología Socio Cultural,2 pasando por el tratamiento crítico de los procesos étnicos identitarios y de la etnicidad, hasta los aportes para la construcción de una antropología crítica, emancipadora y latinoamericana.

Uno de los debates sostenidos al interior del campo filosófico, y también en el seno del campo científico de las ciencias sociales, se concentra alrededor de las modalidades de construcción de un diálogo intercultural, capaz de superar fundamentalismos políticos, ideológicos, étnicos y religiosos. Nuestra perspectiva de abordaje será la de una antropología socio cultural crítica y emancipadora.

El propósito fundamental de la Antropología Emancipadora es el de poner en evidencia, primero, e investigar, después, las situaciones histórico - culturales y socio -económicas de opresión realmente existentes en las distintas sociedades. Por supuesto que el desmontaje teórico de tales circunstancias tiene una finalidad deliberada: el interés y la intención de diseñar políticas socio - culturales específicas y racionalmente fundamentadas que permitan trascender dichas situaciones objetivas de opresión.

El principal componente de la Antropología Emancipadora es su carácter crítico en un doble sentido:

a) la evaluación de las diferentes posturas teóricas planteadas dentro de un contexto problemático mediante un razonamiento capaz de discriminar matices argumentativos y de colocar cuñas que permitan desmontar aspectos discursivos parciales.

b) la puesta en evidencia de supuestos ideológicos subyacentes, de intereses políticos y económicos individuales, grupales y sectoriales que pretendan la manipulación de los marcos teóricos que sirven de soporte y guía a los discursos argumentativos y de los mismos procesos histórico - psicolingüísticos y socioculturales que estos describen y explican (H. Vázquez 2000: 17).

Por otro lado, tal perspectiva implica descentrarse de la epistemología de las ciencias sociales construida en los países centrales, resquebrajar los paradigmas teóricos dominantes a través de un pensamiento crítico y emancipador, ubicándose, a partir del

2 Consultar Vázquez, Héctor 2014 Epistemología de las ciencias sociales y las falsas dicotomías entre subjetivismo /objetivismo, explicación / comprensión, monológico / dialógica Revista de Epistemología y Ciencias Humanas No6. ISSN: 1852-625X. Grupo Ianus. Docentes de la Universidad Nacional de Rosario y Universidad Nacional del Litoral pagina Web 
proceso de investigación situado aquí y ahora, en una perspectiva periférica capaz de reflexionar por fuera de las elaboraciones teóricas de la "civilización noratlántica" $(\mathrm{H}$. Vázquez. Y M. Bigot 2013).

\section{Cultura, sociedad, lengua y percepción: la razón situada.}

El concepto de cultura es uno de los más trabajados en antropología sociocultural y en sociología, según Gilberto Giménez (2002: 18 y 19) cultura es "la organización social de significados interiorizados por los sujetos y grupos sociales, y encarnados en formas simbólicas, todo ello en contextos históricamente específicos y socialmente estructurados". Símbolos y significados, entonces, se encuentran culturalmente contextualizados a través de la triple relación entre sociedad, lengua y percepción de lo real.

Las correspondencias e interrelaciones entre categoría gramaticales y categorías de pensamiento, han sido expuesta (por) y debatida (entre) lingüistas, sociolingüístas, etnolingüístas, psicolingüistas, antropólogos sociales y filósofos. La lista es inmensa y la controversia acerca de la naturaleza de estas interrelaciones agotó las páginas de libros extensos y lucidos.

Al interrogante, ¿Es posible el pensamiento sin lenguaje? Respondemos: lenguaje y pensamiento no son exactamente lo mismo pero se co-constituyen. En efecto, el proceso de percepción de lo real (lo que se encuentra fuera del sujeto que percibe, sea tal sujeto individual o colectivo) se organiza de modos complejísimos en el que convergen símbolos y pautas culturales que delimitan el contexto que permite la percepción. Toda percepción resulta, entonces, histórica y culturalmente contextualizada.

La organización gramato-semántica de cada lengua, peculiar y especifica, opera como sistema lógico/clasificatorio de la experiencia inscribiendo lo percibido al interior de un sistema de referencia.

En su texto Catégories de la pensée et catégories de la langue, E.Benveniste (1958:4), asume que :

«a) fue la estructura de la lengua griega la que permitió a Aristóteles construir su metafísica; b) La lengua griega posee el verbo ser, el verbo ser no es común a todas las lenguas; c) Si se analiza una lengua de distinta estructura que la griega (la EWE, por ejemplo, es necesario valerse de cinco verbos para significar el verbo ser griego, d) Al hacer la descripción del verbo "ser" de la lengua EWE, cometemos un hermoso ejemplar de antropomorfismo. De otro modo, Platón, Parménides y Aristóteles nunca hubieran hecho su metafísica si hubiesen hablado la lengua EWE, pues el "ser" de esta lengua no es el ser de la lengua Griega"

La lingüística y la etnolingüística se han desarrollado mucho desde entonces, pero la concepción de la estrecha relación entre categorías del lenguaje y categorías del pensamiento, y de que la lengua es el más importante de los sistemas simbólicos porque organiza, a los otros ya que opera como segmentadota de la percepción de la experiencia sensible, persiste todavía.

De un modo parecido, M. Bigot y G. Fernández Guizetti (1977) han explicado como el análisis de los deícticos (morfemas que expresan relaciones espacio temporales) de la lengua qom (toba) supone el correlato mental de una diferente concepción del espacio y del movimiento comparándola con el castellano. En efecto, la temporalidad se encuentra sometida al movimiento. No hay aquí una oposición entre espacio / tiempo.

Las categorías Espacio y Tiempo no son las mismas en todas las culturas. Las nociones tiempo y espacio mítico de las culturas sin escrituras son muy distintas a las de las culturas europeas contemporáneas. A modo de ejemplo, afirmamos que entre los sioux de América 
del Norte el número 4, base de su sistema numérico, tiene carácter sagrado debido a su relación con los cuatro puntos cardinales pero además poseen esa misma cualidad, los números 5 (cenit), el 6 (nadir) y el 7 (el hombre que cuenta).

Para la civilización occidental el Tiempo es tiempo histórico. La temporalidad, condición primera de lo histórico, se caracteriza por la noción de irreversibilidad y de realidad. Lo histórico es pasado irrecuperable en tanto pasado, y es real en tanto que existe en un momento dado de la duración histórica, y no en otro. Si es cierto que el tiempo histórico es heterogéneo pues introduce las categorías de pasado, presente y futuro (estas categorías son utilizadas con el propósito de establecer niveles de referencia), el supuesto filosófico en el que se basa es el de la homogeneidad: un fluir continuo e incesante. De modo tal que occidente define al tiempo como devenir y es a partir de esta categoría que el tiempo se torna acumulativo: el pasado se proyecta en el presente y el presente en el futuro. Se trata de la flecha del tiempo.

Recordemos que para Aristóteles el espacio es aquello que rodea a la cosa y se caracteriza por la extensión. Esta noción de espacio no puede separarse de la sustancia aristotélica (ousía) y es la que impera en el sentido común de los hombres insertos en la cultura occidental. Por supuesto estamos hablando del espacio euclidiano tridimensional, el que, como Vygotsky (1985), L.S. y Luria, A.R. (1980) lo demostraron, se aprende en la escuela y no es consustancial al pensamiento prealfabetizado.

La noción del sentido común occidental de tiempo y espacio es la dominante en la física matemática de Newton. No obstante la lingüística comparada primero, la etnología y la psicología comparada, después, demostraron que otras lenguas, otras mentalidades y otras culturas, diversas de la occidental, poseían nociones de espacio y tiempo divergentes, distintos de ella.

Los etnólogos enfatizan que la concepción de tiempo y de espacio que domina el ritmo mental de las culturas no occidentales, aunque heterogéneas entre sí, es muy otra comparándola con la occidental. La concepción del espacio y tiempo mítico inherente a las culturas ágrafas o, expresadas de otro modo, de acumulación de hombres por oposición a las de acumulación de bienes; ya lo dijimos, es muy diferente.

El cosmos mítico, en tanto todo ordenado, estructura una particular cosmovisión, se articula mediante categorías espacio temporales muy distintas a las de la civilización occidental.

El espacio mítico no está dado por "aquello que rodea a la cosa", no se caracteriza por la "extensión" ya que trasciende el ser individual pero encuentra sus límites en lo social: se trata del espacio comunitario. Este espacio comunal es sagrado, pues la sociedad ha sido creada por los dioses, o en pueblos donde estos no existen por fuerzas sobrenaturales. Más allá de este espacio ordenado se encuentra el caos, habitados por los dueños del Mal.

Al interior de este espacio sagrado, se encuentra un sub-espacio donde lo "sagrado" se expresa con mayor intensidad porque se percibe la presencia de fuerzas sobrenaturales. Este lugar especial será el del culto.

Del mismo modo que el espacio mítico, el tiempo mítico es también tiempo social. El tiempo que rige el ritmo mental de todos los individuos que componen la etnia. Así el tiempo del individuo se disuelve en un tiempo colectivo.

El tiempo mítico es el tiempo primordial de la creación de la etnia, y de tal cualidad deriva su condición de "sagrado" pero además es concreto y homogéneo. Entonces, si el tiempo de la creación es uno e invisible, mientras que el tiempo existencial es percibido como una pluralidad de tiempos diferentes y distintos entre sí, puesto que es concreto y homogéneo, ¿de qué modo se relacionan uno con el otro? Es que el tiempo existencial (que siempre es 
el tiempo social organizado por el grupo étnico) aparece como una manifestación concreta y particular del tiempo primordial que lo crea y le confiere sentido.

Los hombres al asimilar el ritmo cíclico de la vida vegetal y animal, de los movimientos astrales, han elaborado, de un modo concreto y contextual, tales nociones de espacio y tiempo propias de las sociedades cazadoras-recolectoras y agrarias.

Falta indicar, para completar esta breve descripción, que mediante el culto, el tiempo existencial se inserta en el tiempo sagrado y así adquiere tal carácter. Por medio del culto, se encarnan los mitos a través de los rituales, se recrea el orden primigenio del mundo y se quiebra toda dicotomía entre tiempo originario y tiempo existencial.

Las categorías del pensamiento, la organización lógica de las formas reales del pensar se encuentran, por lo tanto, contextualizadas histórico social y psicoculturalmente. La razón se encuentra situada. Cómo lo proponen C. Geertz (1987), R. Rorty (1990) y P. Winch (1994), entre otros, esta razón situada se opone al concepto de Razón Universal. Como nosotros mismos lo planteamos (1982 y 1994), si la razón se encuentra situada nos encontramos ante una pluralidad de sistematizaciones racionales diferentes que organizan funciones racionales alternativas y plasman cosmovisiones diferentes de la occidental.

Obviamente, no sólo las categorías lógico-conceptuales que organizan los modos reales del pensar constituyendo una pluralidad de sistematizaciones racionales se encuentran social, histórica, psicolingüística y culturalmente condicionadas. La sensibilidad, la afectividad, el carácter y la personalidad de los miembros del grupo étnico. Durante los procesos de endoculturación se introyectan en los miembros de cada grupo étnico un sistema de valores, de normas morales y de pautas de conductas que modelan tanto su temperamento como su construcción identitaria: la apropiación de un sistema de significados simbólicos que lo constituyen como persona.

\section{Particularismo versus universalismo.}

La cultura opera como gestalt, como unidad totalizadora que condiciona y establece límites tanto a la percepción de la realidad como al carácter y la personalidad de los miembros del grupo étnico culturalmente marcado. Los sistemas de valores, los códigos morales y las normas que regulan las interacciones sociales entre hombres y mujeres, cosas, animales y el medio ambiente no escapan a tal condicionamiento contextual. Del mismo modo, la cultura moldea la identidad grupal de cada etnia. De tal modo, la identidad étnica se construye como identidad colectiva en la que se subsumen, disolviéndose e integrándose las identidades individuales de los miembros de cada grupo étnico.

Resulta claro entonces que asumimos una posición particularista que se opone claramente a la universalista. El universalismo plantea la existencia de una naturaleza humana universal, como lo quería el iusnaturalismo, que fundamentará su concepción de la igualdad en las necesidades comunes que todos los hombres tienen puesto que comparte una naturaleza humana común a todos ellos. Para nosotros no debe substancializarse el concepto naturaleza humana sino, por lo contrario, existencializarse; ubicándolo en las coordenadas espacio temporales y socioculturales (Vázquez: 1982 y 1995). En la concepción universalista subyace un eurocentrismo exagerado que adopta como modelo universal de la razón, la sistematización racional europea de la Ilustración y que supone que cualquier hombre, en cualquier momento de la historia y en cualquier cultura, organiza su razón y por lo tanto sus pensamientos, de acuerdo a las categorías lógicas de la razón europea. Por supuesto que 
desde la perspectiva del racionalismo esto vale también para las normas morales y jurídicas.

¿Es nuestro particularismo gnoseológicamente relativista? No lo es, sostenemos que no hay una inconmensurabilidad fuerte entre las diferentes culturas sino una inconmensurabilidad débil. Del mismo modo que plantamos la existencia de un condicionamiento psicolingüístico y cultural y no una determinación. El concepto de condicionamiento alude a un estado provisorio de la percepción, el carácter y la personalidad. La categoría de determinación refiere a una situación constitutiva inmutable, que no cambiará.

En un texto que denominamos Etnología del Conocimiento (1987 y 1995) describimos y explicamos exhaustivamente la lógica de la dinámica de las sistematizaciones simbólico-racionales y de la génesis de los esquemas lógico-cognitivos. Diremos solamente al respecto que los conflictos y contradicciones al interior de cada grupo étnico, por un lado, y por otro, los contactos lingüísticos culturales entre culturas diversas y las interrelaciones socioculturales que se establecen entre ellas, a veces de dominación/sometimiento, quiebran las sistematizaciones simbólicas tradicionales y, en consecuencia, los esquemas cognitivos configurados, construyendo mediante un proceso de reinterpretaciones, nuevas sistematizaciones simbólico racionales que se muestran con mayor independencia del contexto social inmediato que anteriormente las generó, incorporando nuevos elementos, rasgos, palabras y símbolos que las tornan más abarcativas y que mediatizan el control cultural que el grupo étnico ejerce sobre ellas.

Dentro de este discontinuo, conflictivo y contradictorio proceso interactivo de desarrollo ramificado; los esquemas lógico-cognitivos que conformas las sistematizaciones racionales de cada grupo étnico se modifican, del mismo modo que sus respectivas cosmovisiones. Moviéndose, por así decirlo, desde una actividad mental que privilegia la percepción objetal concreto-situacional y la referencia experiencia personal inmediata hacia nuevas modalidades de percepción de la realidad y de clasificación de la experiencia que tiende hacia la actividad mental teórico axiomática. Obviamente tales tendencias pueden coexistir dominando una y sometida otra.

Algo similar acontece con la construcción de la "identidad étnica" en constante proceso de gestación. Precisamente, por la naturaleza intrínseca de la génesis sociocultural y psicolingüística que recrea esta identidad colectiva, nos parece más conveniente y riguroso suplantar el concepto de "identidad" étnica por el de procesos étnicos identitarios (Vázquez 2.000). De modo que la "identidad étnica" sólo se muestra como tal en un momento dado de dicho proceso. Se expresa bajo la forma provisoria que asumen las contradicciones socioculturales en un momento dado de las relaciones socioétnicas. A nivel lógico se manifiesta como el punto de desfasaje del concepto consigo mismo: el núcleo de reversión dialéctica que se reconoce en su negación. En constante proceso de remodificación, la nueva "identidad" se asienta sobre su contradicción mediante la supresión de rasgos culturales, pautas de conductas, de valores tradicionales y del sincretismo. Generando, así, profundas contradicciones intraétnicas e insertándose en un nuevo orden sociopolítico con el que se articula, generalmente sometida a un proceso de dominación, y con el que mantiene relaciones conflictivas de oposición y de resistencia.3

3 La crítica al esencialismo con relación a la identidad étnica no debe confundirse con la simple y automática eliminación de los rasgos y de las características culturales que se transforman en otros (los que también adquieren el mismo tipo de existencia objetiva) siguiendo 
Si desde un punto de vista sincrónico el particularismo puede parecer relativista; desde una perspectiva diacrónica, gestada por los ritmos de cambio de los procesos históricos, tal "relativismo" se disuelve.

Por otro lado, "El dilema particularismo versus universalismo con relación a la diversidad étnica realmente existente y la "verdadera" naturaleza de lo ético y de lo moral se presenta como falso cuando no se distingue con claridad la diferencia entre ética normativa-reflexión sobre los fundamentos, índole, condiciones de aplicabilidad de las normas morales- y ética descriptiva- la reflexión acerca de la existencia y vigencia de los códigos morales según condicionamiento de tiempo y lugar (sociedadcultura)-. También cuando se propone el abordaje del tema en el contexto del aquí y del ahora, desvinculado de los procesos de dominación-sometimiento y construcción, descontrucción y reelaboración de los sistemas morales. Proceso siempre complejo, multidimensional, que se expande a través de un amplio arco de dominios diferentes que van desde relaciones sociales efectivamente existentes al más abstracto de los códigos simbólicos, como el compuesto por las interacciones entre lengua, pensamiento, sociedad, cultura y percepción.

La oposición individuo/sociedad, individualismo/comunitarismo, es, una vez más falaz. Sobre todo cuando cae de suyo que no tiene sentido el concepto de norma moral fundamentado en la existencia individual. De haber un único hombre en la tierra el problema ético-moral no se plantearía. La moral de tal hombre sería La Moral.

La exigencia de la fundamentación de lo moral deriva de las interacciones sociales entre los hombres: de la vida en sociedad. El problema de la naturaleza de lo moral constituye un dilema social" (Vázquez 2.000: 119 y 120)

Resulta claro entonces que las reglas morales se inscriben dentro del contexto étnico, y, en consecuencia, son particulares y específicas para cada pueblo. Sin embargo, nuevamente, en el plano diacrónico tales reglas, cambian. Se hacen otras. Desde el punto de vista de una Antropología Crítica y Emancipadora no todos los sistemas morales tienen la misma validez.4 Es aquí, entonces donde se instala la reflexión sobre esta temática a partir del Diálogo Intercultural.

Resulta importante consignar que R. Rorty (1998:132) fundamenta la emergencia de la noción de obligatoriedad moral de la aceptación y el reconocimiento de los otros culturales en los sentimientos y afectividad antes que en la racionalidad, en un proceso de educación sentimental. Para él "la difusión de la cultura de los derechos humanos responde mucho más a un "progreso de los sentimientos" que a un mayor conocimiento de las exigencias de la ley Moral" (1998: 132).

sus propios ritmos y lógicas específicas de cambio en orden a su respectiva naturaleza sociocultural y psicolingüística.

4 En "Aproximaciones a una ética de la cultura" Luis Villoro hace notar que "una ética sólo puede referirse a comportamientos concientes y e intencionales (1993:135). De este modo apela al pensamiento crítico plantea la falsa dicotomía universalismo / particularismo y asume que una cultura: "satisface necesidades, cumple deseos y permite realizar los fines del hombre", expresando una visión del mundo cargada de sentido, guiando conductas y actitudes, orientando valores, integrando los individuos a la colectividad y adecuando los medios para la puesta en práctica de tales valores y fines. De modo que: "una cultura será preferible a otra en la medida que cumpla mejor esa triple función de expresar, de dar sentido y asegurar el poder de nuestras acciones" (135 y 136). 
Así emerge, estrechamente vinculada a la temática de la vigencia de códigos morales pluriculturales, la de los derechos diferenciados según cultura $\mathrm{y}$, también, la del cuestionamiento a la noción eurocéntrica de los Derechos Humanos (DD. HH)5.

\section{Los derechos diferenciados según cultura.}

Mientras la concepción occidental del derecho se construye desde el individuo como sujeto de derecho, es la concepción de grupo, la visión colectiva de la titularidad de los derechos la que domina en poblaciones no occidentales tal como la de los pueblos originarios latinoamericanos. En efecto, estos derechos vinculados a la propiedad colectiva de la tierra, a las normas emergentes del derecho consuetudinario indígena, se vinculan con los miembros de un grupo étnico determinado. Su titularidad puede ejercerse de modo individual, colectivo o colectiva e individualmente al mismo tiempo. Estos derechos étnicos, conjuntamente con las reglas morales sistematizadas en códigos consuetudinarios, constituyen la armazón cultural que confiere la estructura identitaria de cada grupo etnico.

Se ha tornado clásica y de cita imprescindible la sistematización de W. Kymlicka (1996) con relación a la problemática de los grupos étnicos y de las nacionalidades enclavadas en una sociedad más abarcadora distingue entre:

1.- Derechos de autogobierno: Este concepto se vincula, muy estrechamente, con el de autodeterminación. En este caso son las minorías nacionales las que tienden a reivindicar capacidad de decisión sobre aspectos que ellas consideran constitutivas de su cultura, tales como la lengua, la educación, la organización familiar, el propio derecho (visto por ellas como alternativo o con distintos grados de alternatividad), etc.

2.- Derechos poliétnicos: referidos a la protección de normas de conducta, creencias, cultos y rituales religiosos

3.- Derechos especiales de representación merced a la pertenencia grupal: facilitan la participación de los grupos nacionales y étnicos minoritarios en defensa de sus intereses culturales comunes mediante la participación en las instituciones de la sociedad mayor.

5 En 1948, hacia el principio de la segunda postguerra, la comunidad internacional produce la Declaración Universal de los Derechos Humanos. La declaración de las Naciones Unidas tiene antecedentes en los debates de 1787 sobre la Constitución de los Estados Unidos, realizados en Filadelfia en la que se produjo un articulado que no firmaron todos los representantes constituyentes. Y, posteriormente, en la declaración francesa de 1789. Tales declaraciones se fundamentan en una concepción iusnaturalista que plantea la existencia de una: "naturaleza humana universal". La declaración de las Naciones Unidas postula: "el reconocimiento de la dignidad intrínseca de los derechos iguales e inalienables de todos los miembros de la familia humana". Por lo tanto se trata de derechos que se reconocen a todos los hombres por igual. No son exclusivos de algunos hombres, de algunos grupos sociales o étnicos, de algunos ciudadanos y otros no, de algunos estados y otros no; sino de todos los hombres y mujeres del mundo. Además se trata de derechos inalienables. Esto es, derechos cuyo titular no puede perder ni siquiera renunciando ya que se trata de derechos a los que resulta imposible renunciar.

La doctrina jurídica referente a los Derechos Humanos ha ido ganando espacio en el Derecho Positivo de los estados. A los derechos individuales y políticos se han agregado los derechos económicos sociales y culturales $\mathrm{y}$, posteriormente, los derechos al medio ambiente, al desarrollo, los derechos de género y del consumidor. Dentro de estos derechos nos interesan particularmente los inherentes a las "minorías". Más precisamente los de las "minorías étnicas". 
Tales derechos son de gran ayuda y apoyo al propósito de reducir la vulnerabilidad de las minorías étnicas y nacionales.

Una primera aclaración necesaria sobre el tema es que si estos derechos funcionan como "derechos colectivos". En realidad, no son estrictamente hablando "derechos colectivos", en tanto y en cuanto, no se trata de derechos opuestos y en conflicto con los "derechos individuales". Una segunda aclaración necesaria es que la categoría de "derechos colectivos" resulta: "extensa y heterogénea." Comprende los derechos de sindicatos y corporaciones; el derecho a establecer litigio como acciones de clase; el derecho de todos los ciudadanos a un aire no contaminado, etc. Estos derechos tienen poco en común, y es importante no mezclar la idea de una ciudadanía diferenciada en función del grupo con la miríada de otros temas que surgen bajo la definición de "derechos colectivos."

Lo más importante de todo es que la terminología de los derechos colectivos incita a la gente a elaborar supuestos erróneos sobre la relación entre la ciudadanía diferenciada en función del grupo y los derechos individuales. Es natural dar por supuesto que los derechos colectivos son derechos ejercidos por las colectividades, como algo opuesto a los derechos ejercidos por los individuos, y que los primeros entran en conflicto con los segundos." (1996: 57 y 58).

Resulta imprescindible discriminar entre: "derechos colectivos" y "derechos diferenciados en función de pertenencia a un grupo".

W. Kymlicka (1996:58), desde los márgenes del liberalismo observa que:

“...esta retórica sobre derechos individuales versus derechos colectivos es de poco ayuda. Debemos distinguir entre dos tipos de reivindicaciones que un grupo étnico o nacional podría hacer. El primero implica la reivindicación de un grupo contra sus propios miembros; el segundo implica la reivindicación de un grupo contra la sociedad en la que está englobado. Se puede considerar que ambos tipos de reivindicaciones protegen la estabilidad de comunidades regionales o étnicas, pero que responden a diferentes fuentes de inestabilidad. El primer tipo tiene el objetivo de proteger al grupo del impacto desestabilizador del disenso interno (por ejemplo la decisión de los miembros individuales de no seguir las prácticas o las costumbres tradicionales), mientras que el objetivo del segundo es proteger al grupo del impacto de las decisiones externas (por ejemplo, las decisiones políticas y económicas de la sociedad mayor). Para distinguir estos dos tipos de reivindicaciones, denominaré a las primeras "restricciones internas" y a las segundas" protecciones externas".

Está claro, entonces, que las restricciones internas tienen una aplicación endógena, es decir al interior del grupo étnico y se refieren al proceso de control social sobre sus miembros. Vigila las posibles conductas (y opiniones) que renieguen o se opongan a las costumbres y a las tradiciones y creencias dominantes que son juzgadas por éste como propias y valorizadas como fundamentales para la cohesión grupal. Las protecciones externas, en cambio, refieren a la necesidad de autodefensa del grupo étnico con relación a las políticas y actitudes que promueve la sociedad global en la que el grupo se enclava. Se trata aquí de un contexto de relaciones interétnicas, de relaciones intragrupales, articuladas dentro de un esquema de relación / sometimiento y promueve el resguardo de grupos étnicos y de las nacionalidades ante las pretensiones de los estados de utilizar el poder político que les es propio con el propósito de afectar su unidad territorial o étnica.

\section{Cuestionamiento a la noción eurocéntrica de los Derechos Humanos (DD. HH).}

La Carta Constitucional Africana de DD. HH. Y de las Personas 1981 (The African Charter on Human and People's Rights de 1981, el Cairo); la Declaración de los DD. HH. en Islam de 1990 (Declaration on Human Rights in Islam de 1990), y La 
Declaración de Bankok y de Túnez de 1993 (Bangkok Declaration y la Tunis Declaration de 1993) cuestionan el planteo eurocéntrico de la Declaración "Universal" de los Derechos Humanos, la que por supuesto no es realmente Universal por que deja de lado la concepción africana y la asiática de los DD. HH.

Con sus matices diferenciales tales declaraciones hacen notar que mientras que los Derechos Humanos son de naturaleza universal, deben considerarse contextualizados histórica y culturalmente. Los principios y normas necesitan recoger las significaciones inherentes y específicas de las naciones y regiones particulares, sin desligarlos de las tradiciones morales y religiosas. En tales tradiciones el grupo tiene más importancia que los individuos, si se lo considera desde la perspectiva occidental, que, por ejemplo, John Rawls (1998) expresa sobre los principios de las justicia.

La 19 Conferencia Islámica de Ministros de Relaciones Extranjeras (cancilleres), en la Sesión referida a la Paz, Interdependencia y Desarrollo, realizada en El Cairo, Egipto, de 9-14 Muharram 1141, según el calendario islámico; esto es El 31 de julio al 5 de Agosto de 1990, destaca particularmente que la noción de Derechos Humanos y de Libertad de acuerdo al Islam son parte integrante de la religión islámica y que por lo tanto no pueden desprenderse de ella y a que tales conceptos han sido consignados en el Revelado Libro de Alá.

Resulta claro, además, que los sistemas de valores asiáticos priorizan su naturaleza comunitarista, la conexión armoniosa entre los hombres y la naturaleza, el respeto a las autoridades comunitarias y a la tradición. Subyace en estas declaraciones, al menos así lo estimamos, una desconfianza hacia el "universalismo" europeo, al que se lo vincula con una tecnocracia depredadora del medio ambiente, con el ultra individualismo y al imperialismo capitalista el que intenta dominar culturalmente avasallando y destruyendo la identidad cultural de otros pueblos y otras culturas.

Según Onuna Yasukai (2003) la concepción de los DD. HH. es producto de la visión europea, occidenticocéntrica, la que concibe al planeta como una sociedad internacional. También los conceptos de nacionalidad y de internacionalidad son occidenticocéntricos.

Tal punto de vista etnocéntrico, que trasciende la visión de los estados para instalarse en otros actores sociales como las ONG y Greenpeace, por ejemplo, considera cualquier aplicación que se desvíe de la concepción universalista como un cuestionamiento a los DD. HH. Como alternativa, es imprescindible la construcción de una perspectiva transcivilizatoria Dicha perspectiva permitirá reconocer, interpretar, evaluar, buscar y proponer soluciones a problemas que trascienden los límites nacionales utilizando una sistema categorial de percepción basado en civilizaciones plurales.

Conviene aclarar al respecto que el artículo 28 del Estatuto de la Corte de Justicia Internacional define el concepto "civilización" como: "Los principios Generales de la Ley reconocidos por las naciones civilizadas". Entiende por naciones civilizadas a las naciones europeas. Por lo tanto subyace aquí una visón eurocéntrica.

La Perspectiva transcivilizatoria propuesta por Onuma Yasuaki define el concepto de civilización como un término funcional capaz de asumir que los seres humanos pueden pertenecer simultáneamente a civilizaciones plurales. Las distintas regiones deben identificarse como unidades de civilización basadas en los intereses comunes y culturas o tradiciones culturales que son compartidos por las gentes en la región sin tener en cuenta su pertenencia a diferentes naciones. Ninguna civilización es monolítica. Un problema central es el de los modos en que se debe introducir el concepto de civilización en el discurso de la legalidad internacional. Si a pesar de los procesos de 
colonización, el Principio de No Intervención garantizó, en buena medida, la no ingerencia de los estados occidentales sobre los no occidentales, su declive agudizó la penetración de occidente sobre otras civilizaciones. Con el propósito de que los DD.HH. puedan ser verdaderamente universales, debe incluirse las nociones asiáticas y africanas de DD. HH., argumenta Onuma Yasukai. Desde este punto de vista, es posible apreciar que el universalismo puede corregir los mecanismos regionales. Muchos problemas son básicamente comunes tanto a la concepción universalista de los DD. HH. como a los mecanismos que se implementan regionalmente para su aplicación. Las teorías, dispositivos, prácticas y técnicas para resolver estos problemas pueden ser sugerentes y útiles en uno u otro caso.

Onuma Yakusai no sostiene que la Perspectiva Transcivilizatoria que propone reemplace a la internacional o la transnacional. Tampoco plantea un acercamiento basado en una metodología rígida. Se trata más bien de una perspectiva general dirigida a los problemas globales. Debe adoptarse junto con las perspectivas internacionales y transnacionales. Consiste en una visión multifacética y más equilibrada del mundo, que pueda ser aceptada por sectores sociales más amplios, capaz de proponer ideas más legítimas para resolver los problemas globales.

La Perspectiva Transicivilizatoria desarrollada por Onuma Yasukai tiene puntos de convergencia con la de Eduardo Rabossi (1991) y la de Richard Rorty (1998) vinculados a la necesaria articulación de lo universal y lo regional (lo global y lo local) y a la noción de obligatoriedad moral de la aceptación y el reconocimiento de los otros culturales que ya mencionamos al modo de Rorty.

Se trata, fundamentalmente, de quebrar el logocentrismo de la visión europocéntrica (puesto que es occidente la civilización que hegemoniza el domino político / económico global) pero también de las otras visiones del mundo como la del Islam, la Budista o el la expresada en otras concepciones del mundo en sus amplísimas variantes.

\section{EI Diálogo Intercultural.}

El año 2008 fue, en Europa, el año del diálogo intercultural. En sentido estricto la interculturalidad refiere las relaciones interétnicas mantenidas al interior de un mismo complejo nacional por dos más grupos étnicos. En un sentido laxo, que no compartimos, se vincula con categorías sociales carentes de cualidad étnica tales como género, orientación sexual, grupos etarios, etc.

El fuerte impacto de los flujos migratorios de miembros de grupos étnicos y de poblaciones carenciadas que profesan religiones vinculadas a civilizaciones no occidentales hacia la Comunidad Europea, la exclusión social de los miembros de las poblaciones étnicas enclavadas en los países europeos, el tratamiento vejatorio y discriminatorio por parte de amplios segmentos sociales de la sociedad local/ nacional $\mathrm{y}$, de las mismas instituciones estatales, hacia estos emigrantes y sus descendientes, provocaron alzamientos, rebeliones y choques étnicos de altísima tensión social. Basta con recordar los tumultos emergentes y los estallidos sociales en Paris y en otras ciudades francesas de los hijos, de nacionalidad francesa, por supuesto, de emigrantes marroquíes.

En América Latina, la interculturalidad se liga, muy especialmente, con los enclaves de las poblaciones indígenas y de las poblaciones emigrantes de países fronterizos, en las distintas sociedades nacionales. 
El concepto de diálogo intercultural, tal como nosotros lo comprendemos, hace referencia a la creación de un espacio de interacción sociocultural que intenta el logro de una comprensión mutua entre los miembros de culturas diferenciadas.

La más adecuada, articulada, y riguosa modalidad para facilitar tal diálogo es la Educación Bilingüe e Intercultural. La decisión política de los estados puede introducir políticas públicas de gran alcance que facilitarían enormemente la producción efectiva del diálogo intercultural.

Según Asma Jahangir (Entrevista en Internet. Ref.: 20080623STO32401): "el diálogo intercultural es abrir espacios a una diversidad de voces". Propone utilizar los medios de comunicación, el cine, el teatro, la literatura y las artes como medio masivo de promoción del diálogo intercultural. La idea es difundir la naturaleza de las diferencias ètnico-culturales. Partiendo del concepto de que la igualdad, la verdadera, se articula a partir de la diferencia.

"El reconocimiento de la diferencia y de lo diferente lleva implícito una actitud ética que en nada tiene que ver con su identificación con la categoría de desigualdad. Todo lo contrario, supone una actitud valorativa de reconocimiento del otro cultural. La defensa del derecho de las "minorías" se articula con la necesidad de ensanchar la idea de igualdad mediante la defensa de los derechos específicos capaces de "acomodar" diferencias y corregir desigualdades. Se trata de los derechos que favorecen la inclusión de los grupos sociales excluidos o en proceso de exclusión. Tylor (1993), Walzer (1998), Kymlicka (1993) y muchos otros autores asumen que el concepto de igualdad es perfectamente compatible con el de diversidad y / o pluralidad.

Exactamente ese es nuestro criterio. La antropología política ha de admitir la lógica de esta cuasi asimilación. La problemática de la igualdad versus desigualdad y de la igualdad versus diferencia se ha convertido en una temática que emerge con inusitada frecuencia en la filosofía política contemporánea. La cuestión de la igualdad y de la libertad se erige en la otra cara de las temáticas enunciadas" (Vázquez: 2007: 23 y 24)

Según Tylor identidad y reconocimiento son conceptos que se autoexcluyen, por lo tanto lo que sigue es que, en el dominio de lo público, la noción de igualdad debe pasar, en las sociedades democráticas, por la asunción de lo diferente. Del reconocimiento de la identidad única del individuo y del grupo. Tal reconocimiento es reconocimiento del "hecho de que es distinto de todos los demás" (Tylor: 1993:61). Lo que se reconoce entonces es aquello que "no es universalmente compartido" (Tylor: 1993:61). Esto trae como consecuencia la necesidad de un tratamiento diferencial. En este caso diferencia e igualdad son conceptos compatibles, casi asimilables.

La concepción multiculturalista al superar el monismo cultural abre la posibilidad del díálogo intercultural al suponer el "reconocimiento del otro". Reconocimiento que se realiza con el propósito de "acomodar" diferencias culturales dentro del contexto hegemónico de la sociedad "mayoritaria" de raigambre cultural occidental. Ni Tylor ni el mismo W. Kymlicka superan esta visión.

A partir de sus investigaciones socioantropológicas y etnolingüísticas en comunidades aborígenes mexicanas R. Hamel (1998) propone un modelo pluricultural en el que los actores sociales, tanto de las sociedades dominantes como de los pueblos originarios, asumen las diferencias étnicas y lingüísticas como factores de enriquecimiento cultural y como recursos valiosos para la sociedad en general.

De modo que ya no se trata del reconocimiento de las diferencias sino de asumir la pluralidad cultural insertando la propia cultura como una más entre otras realidades culturales existentes. Obviamente compartimos esta propuesta. 


\section{Conclusiones.}

La diversidad cultural es un hecho histórico, social y cultural que se debe asumir como tal. Las culturas no constituyen organizaciones sociales y simbólicas cerradas en sí mismas. Aun en sociedades sin clases sociales existen conflictos plantados por la distribución de bienes, las relaciones de parentesco, las alianzas etarias entre algunos de sus miembros con otros miembros de grupos socioétnicos distintos, y la dominación de un grupo étnico sobre otro. Hay conflictos. También las sistematizaciones racionales inherentes a cada grupo étnico cambian, al variar, desde el habla hacia el sistema de la lengua, las categorías gramaticales y lógicas de cada sistema lingüístico. Por lo tanto, solamente existe un tipo débil de inconmensurabilidad cultural. Esto, precisamente, permite la comunicación intercultural y hace posible la apertura de un diálogo.

Este diálogo tiene múltiples dimensiones. Se muestra en el mismo proceso de la "investigación transcultural donde se intervinculan visiones del mundo diferentes, se va desarrollando, más o menos paulatinamente, un proceso de relativo acercamiento de los respectivos marcos conceptuales (de los investigadores y del grupo social sobre el que el proceso de investigación recae) a partir de la penetración cognitiva de los investigadores. Ella va abriendo "espacios" simbólicos que permiten iniciar un proceso de convergencia cultural capaz de generar nuevos marcos referenciales en los que se comparten algunos criterios comunes. Esta relación de intersubjetividad se facilita mucho cuando los actores sociales con los que los investigadores interactúan tienen competencia en el manejo de la lengua del investigador y viceversa". Héctor Vázquez (2005). Uno de los dilemas centrales al que se enfrenta los investigadores (sucede lo mismos al establecerse cualquier modo de diálogo intercultural entre miembros de grupos étnicos diferenciados) es el tomar partido (aceptando o rechazando) por normas morales vigentes que resienten y chocan con su concepción de la moral tales como la existencia de grupos étnicos que, como en muchas culturas del África negra propician la ablación del clítoris o como en el caso que plantea R. Cardoso de Oliveria (1993) el del infanticidio entre los tapirapé. Este es un debate que se reabre constantemente en el dominio de la Antropología Sociocultural y Política, el de la Ética y el de la Filosofía y Sociología Política. Hemos consignado nuestro parece en Héctor Vázquez (2.000).

Cardoso evoca a Groenewold a través de Apel, y sin dejar de reconocer la grandes dificultades políticas y hermenéuticas para la generación de una Ética Planetaria- hace suya la propuesta de distinguir tres esferas sociales (articuladas en tres niveles. micro, meso y macro) con el propósito de "observar la actualización de los valores morales". De modo que "en la micro esfera las normas morales poseen carácter particular y siempre pueden ser observadas en las instancias más íntimas (como las que regulan la vida sexual, por ejemplo). Si en la primera esfera el ideario relativista de la antropología fácilmente cubre de buenos argumentos la intocabilidad de los valores morales contenidos en esas normas, no siendo difícil para el antropólogo indigenista defender su preservación; ya en la macro esfera ese mismo indigenista va a encontrar mayor dificultad en las defensa de ciertas normas particulares- como el infanticidio entre los tapirapé- que infringe una ética planetaria en el cual ese mismo infanticidio se observa desde una ética universalista, por lo tanto como un crimen contra los derechos humanos". Por supuesto, los antropólogos ponen especial esmero en evitar la manipulación del parecer, el bienestar y los intereses de las personas afectadas, dialogando con ellos sobre sus intenciones y deseos de producir modificaciones sobre sus modos de vida. No obstante cierta convergencia de perspectivas, hay algo más que una diferencia de matices entre la postura de Cardoso de Oliveria y la nuestra. Por un lado, relativizamos el valor absoluto de las normas morales universales a su 
apreciación crítica por los antropólogos investigadores, y por otro lado, su concepción aparece muy apoyada en la concepción de J. Habermas sobre la situación ideal de habla, que criticamos en Héctor Vázquez (1995, 2000 y 2005). Es partir del diálogo intercultural gestado entre investigadores e interlocutores que unos y otros podrán evaluar los grados de aceptación o rechazo y las posibilidades de cambio de las normas morales vigentes en las culturas diversas. Algo similar ocurre acerca de los Derechos Humanos los que, según E. Rabossi (1991) han de considerarse en dos planos: el local y el global articulando lo regional con lo universal y la capacidad ejecutiva de los mismos con relación con relación a los aspectos políticos que condicionan su práctica efectiva, los que no dejarán de incidir en sus desfazajes que se produzcan en la vigencia de los DD. HH. con relación con su ideal.

Para finalizar insistimos en la necesidad de la Educación Intercultural, que ya es obligatoria en casi todos los países latinoamericanos. No solamente ha ser bilingüe y dirigida a los niños aborígenes sino que, además, debe ser planteda como canon en todo el sistema escolar y hacia el conjunto de la sociedad.

\section{Bibliografía.}

BIGOT. Margot y FERNÁNDEZ GUIZZETTI, Germán. Elementos de etnosemántica toba: sus proyecciones en la gramática textual, en la teoría de la cosmovisión y en la educación bilingüe. Inédito.

CARDOSO DE OLIVEIRA, Roberto 1993 “ Etnicidad y las posibilidades de un ética planetaria”, en Antropológicas No 8. México. UNAM.

GEERTZ, Clifford 1987 La interpretación de las culturas. GEDISA. Madrid.

GEERTZ, Clifford 1994 Conocimiento local. PAIDOS. Barcelona

GEERTZ, Clifford 1988 “Antiantirelativismo".En Revista Brasileira de Ciencias Sociais. $\mathrm{N}^{\circ} 8$ Vol. 3 ANPOCS. Brasil.

GIMÉNEZ, Gilberto 2002 “Culturas híbridas en las fronteras norte?” En Senderos del pensamiento social, coordinación de F. Flores. México. Ediciones Coyoacán

HAMEL, Ranier, E 1998 "Políticas del lenguaje y estrategias culturales en la educación indígena", en Educación indígena hoy. exclusión y diversidad. Instituto Estatal de Educación Pública. Oaxaca.

HABERMAS, Jürgen 1988 La Lógica de las Ciencias Sociales. Ed. Tecnos. España

HABERMAS, Jürgen 1990 Pensamiento postmetafisico Ed. Taurus. México.

HABERMAS, Jürgen 1999 La Inclusión del otro. Ed. Paiadós .Barcelona

KYMLICKA, Will 1996 La ciudadanía multicultural. PAIDÓS. Barcelona. 
LURIA, A.R. 1980 Los procesos cognitivos. -Análisis socio-histórico- Editorial Fontanella, Barcelona.

RABOSSI, Eduardo 1991 "El fenómeno de los Derechos Humanos y la posibilidad de un nuevo paradigma teórico", en El Derecho La Política y La Ética. David Sobrevilla (compilador) Siglo XXI Editores. Argentina.

RAWLS, John 1972 A theory of justice Oxord University Press. Oxford.

RAWLS, John: 1998 "El Derecho de Gentes", en De los Derechos Humanos. Ed. Trotta. España.

RORTY, Richard 1990 El giro lingüístico. Paidós.

RORTY, Richard. 1998 “Derechos Humanos racionalidad y sentimentalidad”, en De los Derechos Humanos . Ed. Trotta. España.

SASSO, Javier 1991 "Comentario a la ponencia de Eduardo Rabossi": " El fenómeno de los Derechos Humanos y la posibilidad de un nuevo paradigma teórico", en EL DERECHO LA POLÍTICA Y LA ÉTICA. David Sobrevilla (compilador) Siglo XXI Editores. Argentina.

TAYLOR, Charles: 1993 Multiculturalismo y la política del reconocimiento. F.C.E. México

VÁZQUEZ, Héctor 2014 "Epistemología de las ciencias sociales y las falsas dicotomías entre subjetivismo /objetivismo, explicación / comprensión, monológico / dialógica". Revista de Epistemología y Ciencias Humanas Nº. ISSN: 1852-625X. Grupo Ianus. Docentes de la Universidad Nacional de Rosario y Universidad Nacional del Litoral. Pagina Web.

VÁZQUEZ, Héctor y BIGOT, Margot 2013 Aportes para una Antropología Crítica y Latinoamericana. Repositorio Virtual de la Universidad Nacional de Rosario: URI http://hdl.handle.net/2133/2660.

VÁZQUEZ, Héctor 2006 "Diferencia, Desigualdad y Estigma" en Revista De la Escuela de Antropología. No XII. Facultad de Humanidades y Artes Universidad Nacional de Rosario. Argentina.

VÁZQUEZ, Héctor: 2005 Antropología Emancipadora, Derechos Humanos y Pluriculturalidad. HomoSapiens Ediciones. Rosario .Argentina..

VÁZQUEZ, Héctor 2000: Procesos Identitarios y Exclusión Sociocultural -la cuestión indigena en la Argentina- Ed. Biblos. Argentina

VÁZQUEZ, Héctor: 1995 Etnologia del Conocimiento. Ed. Almagesto. Argentina. 
VÁZQUEZ, Héctor 1994 La Investigación Sociocultural —Crítica de la Razón Teórica y de la Razón Instrumental-. Biblos, Buenos Aires.

VÁZQUEZ, Héctor 1986 Del Incesto en Psicoanálisis y en Antropología. FCE, México.

VÁZQUEZ, Héctor 1984 Sobre la Epistemología y la Metodología de la Ciencia Social. Universidad Autónoma de Puebla, México.

VÁZQUEZ, Héctor 1982 El Estructuralismo, el Pensamiento Salvaje y la Muerte Hacia una Teoría Antropológica del Conocimiento-. FCE, México.

VYGOSTSKY, L.S. 1985 Pensamiento y Lenguaje. Ed. Pléyade. Buenos Aires

WALZER, Michel 1990 "Nation and Universe" en G. Peterson (comp) The Tanner Lecture on Humans Values. Salt Lake City. U.S. A

WALZER , Michel 1993 "Comentario sobre el texto de Charles Tylor", en C. Tylor. Ob. Cit.

WALZER, Michel 1998 Tratado sobre la tolerancia. Editorial Paidós. Buenos Aires.

WELLMER, Albrecht: 1994 Ética y Dialogo. Anthropos-UAM. México

WINCH, Peter: 1994 Comprender una sociedad primitiva. Ed. Paidós I.C.E. U.A.B. España.

YASUAKI, Onuma: 2003 Transcivilzational Perspective on International Law. Introduction The theme of this annual meeting is "Unity in Diversity: Asian Perspectives on International Law in the 21Century". On the other hand, the theme of the Panel A is given the title of "Universalism and Regionalism in the International Law of Human Rights". Artículo tomado de Internet. Pagina Web. 